\title{
MENTAL ILLNESS IN PARENTS OF PHENYLKETONURIC CHILDREN
}

\author{
Monica D. BLumenthal \\ Mental Health Research Institute, University of Michigan, Ann Arbor, Michigan 48104
}

(Received 1 June 1966)

(Revised 9 December 1966)

PHEnYlKetonuria is a well studied recessive hereditary disease characterized by a deficiency of phenylalanine hydroxylase in the homozygous individual. ${ }^{1}$ Usually the disease is associated with severe mental deficiency, although there have been an increasing number of cases reported with normal or borderline intelligence. ${ }^{2}$ Interestingly enough, many patients who have normal or near normal intelligence appear to suffer from behavioral disturbances, so that some of these have been misdiagnosed as having autism or organic brain damage. ${ }^{3,4}$ Patients with phenylketonuria and severe mental deficiency may also suffer from what appear to be neurotic and psychotic symptoms, although this aspect of the disease has been minimized in the literature. ${ }^{3}$

Relatively little is known about the characteristics of the heterozygous carrier for this disease; that is, the individual who has both one normal and one abnormal gene for phenylalanine hydroxylase formation. It is presumed that such individuals have below normal phenylalanine hydroxylase levels since it has been repeatedly demonstrated that carriers have a reduced tolerance to a phenylalanine load.,5 Whether or not these persons share other biochemical characteristics with the homozygous phenylketonuric, such as reduced serotonin and catecholamine levels, is currently not known. That the former is a good possibility is suggested by the recent accumulation of evidence that phenylalanine hydroxylase is responsible for the hydroxylation of tryptophan, the first step in serotonin formation. ${ }^{6}$ It has been suggested, however, that persons heterozygeous for phenylketonuria are more apt to suffer from psychopathology than other individuals. This hypothesis was originally considered by FøLLING ${ }^{7}$ who found the aunt of one patient and the great aunt of another suffered from schizophrenia. PENrose ${ }^{8}$ furthered interest in the possibility by presenting a large pedigree in which heterozygosity for phenylketonuria and mental illness appeared to be associated. Since that time, $\mathrm{MUNRO}^{9}$ reported the incidence of psychosis in presumed heterozygotes to be approximately twice the rate expected from a survey of a control group of 653 families of idiots and imbeciles. THUM 5 son ${ }^{10}$ in a study of eight families of phenylketonuric patients, reported striking differences between relatives of phenylketonurics and controls. Another author ${ }^{1}$ has estimated that the possible association between heterozygosity for phenylketonuria and mental illness could account for as much as 20 per cent of mental illness. More recently, PERRY et al. ${ }^{11}$ have fo und no difference in the incidence of psychoses, admissions to mental hospitals, personality disorders, alcoholism, suicide or 
crime rate between a group of persons related to phenylketonuric and mongoloid patients.

If it were indeed the case that heterozygosity for phenylketonuria were associated with mental illness, it would be possible to generate a relatively limited number of biochemical hypotheses which could presumably be correlated with the mental illness. However, most of the previously mentioned studies are open to serious criticism on methodological grounds, and the validity of their findings is open to some question. ${ }^{12}$ This paper presents the results of a field study which was designed to investigate the hypothesis that heterozygosity for phenylketonuria is associated with mental illness. These results essentially substantiate the findings of PERRY et al.11

\section{Population}

\section{METHODS}

Persons presumed heterozygous for phenylketonuria (the PKU group) were located through their phenylketonuric children. These children varied in age from 5 to 30 years and were either known to a state home for the mentally retarded or to one of the special education classes conducted by the Department of Public Instruction of the State of Michigan. We were exceedingly fortunate inasmuch as the state institutions had been systematically screened by ALLEN ${ }^{13}$ some 4 years before the onset of our study, and the Michigan Department of Health had just completed a screening program to identify phenylketonuric children in special education classes. The names of the individuals involved were generously made known to us by Dr. Allen and the Michigan Department of Health. These names should have constituted a census of all identified phenylketonuric individuals in the state of Michigan between the ages of 5 and 30. A control group of children with non-phenylketonuric mental retardation (the NPMR group) was picked for the phenylketonuric probands in the following fashion: A random sample of inmates of the institution at which the phenylketonuric child resided was obtained using a sampling rate of one in ten. NPMR patients were then selected from the random sample to match individual PKU patients in age (within 5 years) and I.Q. (within fifteen points). In a few cases, the one in ten sampling rate was not high enough to provide us with a match. In these cases, an NPMR child was selected out of either the nearest age or I.Q. category, depending on which provided the best match.

The rationale behind this method of selecting probands for the NPMR group was as follows: It is known that parents of children with severe mental defects tend to reflect the social structure of the population at large. It is also known that parents of children with milder defects tend to come from the lower socio-economic classes. ${ }^{14}$ In Michigan, the majority of institutionalized patients suffer from mild degrees of defect so that an unadjusted, random sample of an institution is heavily skewed towards lower socio-economic groups. Phenylketonuric patients, on the other hand, largely fall into the lowest I.Q. categories; the average I.Q. of our PKU probands was 22. These families represent social class distributions similar to the general Michigan population. Since social class is one of the variables which has been most frequently related to the incidence of mental illness, ${ }^{15}$ it seemed advisable to select controls to minimize class differences. Consequently, it was decided to match PKU probands with NPMRs on the basis of I.Q. Similarly, the decision to match probands on the basis of age was to provide for comparable age ranges among the parents of the two 
groups; age being a factor in determining whether or not a given individual has had sufficient time to develop the mental illness to be ascertained.

Because of small classes containing children with a relatively large I.Q. range, the selection procedure was modified in the special education classes. Children in these classes usually fell in a 3-year age range and the NPMR child selected was the one whose I.Q. was closest to that of the phenylketonuric proband. Since none of the phenylketonuric children were non-white, all non-white children were deleted from the control groups. In addition, children who had a primary diagnosis of psychosis or familial-cultural mental deficiency were excluded. The last deletion was made primarily because the diagnosis requires that at least one parent suffer from mental retardation, and it was our feeling that this would compound the difficulty in information gathering. Blood phenylalanine levels were evaluated on all retarded children to confirm the presence or absence of phenylketonuria according to the method of WONG et al.,5 or that of LADU and MiCHAEL. ${ }^{16}$

A second control group was chosen since there may be a relationship between some forms of mental retardation and mental illness. ${ }^{17}$ This group consisted of children with cystic fibrosis (CF) who had attended either the University Hospital or the Children's Hospital of Metropolitan Detroit. Names on the clinic lists were sorted into 5-year age categories and selected at a frequency determined by the number of PKU patients in each age group. Because of the early mortality in cystic fibrosis, it was sometimes necessary to use the name of a dead child. Each of the three groups contained sixty-four probands; no two probands represented the same family. In all cases, the parents of the children in the three groups formed the population which was actually interviewed.

\section{Interview}

Our fundamental methodological problem was to find some way of comparing rates of mental illness in the three populations investigated. Since no attempt was made to measure any absolute rates of mental illness in a general population, the primary concern was to develop a reproducible set of tools which could be readily comprehended. In addition, it was important to reduce bias as much as possible throughout the study. For these reasons, a standard interview schedule, designed to evaluate a variety of mental health areas, was constructed. The interview not only elicited information about the respondents themselves, but also about their children, their siblings, and their parents.

The interview schedule was sympathetically oriented to problems generated by the affected child in the family, and its ostensible purpose was to investigate such problems in detail. We hoped, in this way, to motivate the participation of the parents in the interview by tapping some of the feelings that they had invested in the problem of their children's disease. The interview was constructed so as to allow the respondents to ventilate their feelings about the disease, their experiences with doctors, and emotions generated in themselves by the stresses and strains of the chronically affected child. On the whole, respondents met our interviewers with interest and enthusiasm, and many expressed feelings of relief at finally being able to discuss problems with some interested, outside observer. In addition, the interview was designed to provide a sense of psychological continuity to the respondent; for example, the interview began with a discussion of the child's problem, a history of the parents' efforts to seek help, and continued to inquire about specific problems generated by the 
child in the home. In this context, the respondent was asked whether or not the situation about the child had ever made him feel that he was about to have a nervous breakdown. A more detailed inquiry into his mental health followed naturally, and it was a relatively short psychological step to make the same inquiries about his spouse, and later, the rest of his family. With very few exceptions (one interview was conducted in a local bar) interviewing was done at the home of the respondent.

Outside of the formally stated questions in the interview schedule, the interviewers were allowed only non-directive probes such as "What do you mean?" or "What was that about?" although all interviewers were trained to obtain as detailed an answer as possible. The primary hypothesis of the study, i.e. that persons heterozygous for phenylketonuria would be more apt to be mentally ill than the persons in the two control groups, was never conveyed to the interviewers, although they were well aware that we were looking for signs of mental illness in the different families. The interviewers did know whether they were interviewing the parents of a child with cystic fibrosis rather than parents of a child with mental retardation since pretesting had shown that it was not possible to send the same form letter to both groups; and undoubtedly, the interviewers were often aware of whether or not they were interviewing the parent of a phenylketonuric child, although the interview avoided questions about diagnosis.

All interviewing was done by professional interviewers from the Survey Research Center of the University of Michigan who were given a minimum of 2-days' special training in order to acquaint them with the specific interviewing problem engendered by our questionnaire.

\section{Coding}

A formal code book was constructed according to the standard methods used at the Survey Research Center. ${ }^{18}$ A number of descriptive codes were created, usually on the basis of the first fifty interviews. The code categories were checked against a second group of interviews to test for inclusiveness and completeness of the code. In general we allowed for coding a larger number of answers than was necessary so that in most of the interviews, all answers to openended questions were coded. Answers to open-ended questions were coded according to a system of priorities. These priorities were constructed according to three underlying principles: (1) the most clear-cut, obvious sign of mental disturbance received the highest priority while answers that bore tenuous or no relationship to mental illness received the lowest priority; (2) answers that were directly related to the respondent or to his blood relatives were given priority over answers that applied to non-related individuals; (3) concrete and specific answers always received priority over vague and general answers. So, the codes always moved from specific, concrete items that can be assumed to be highly related to mental illness through items that have a less clear-cut psychiatric meaning to answers that are so vague as to have only questionable psychiatric value. All coding was done by specially trained, professional coders from the Survey Research Center.

Only four coders were used in the actual coding procedure since it was felt that due to the length and complicated nature of the code, a considerable amount of learning would take place during coding. And, in fact, both the coding time per interview and the number of 
errors per interview decreased between the beginning and the end of the coding period, showing that the coders did learn. Check coding showed an average of 6.9 errors per interview, each of which consisted of over eighteen eighty-column IBM cards. The coders were not aware of the basic hypothesis of the study, and the code for identifying the primary group to which the interview belonged (PKU, NPMR, or CF) was not correctly interpreted by the coding staff during coding.

After the interview had been coded, data relevant to particular problem areas were collected into two sets of indices. The first set was our mental health indices, the details of whose construction will be discussed elsewhere. ${ }^{19}$ Briefly, these consisted of a scoring system designed to evaluate data relevant to drinking problems (Alcohol Index), depression (Depression Index), perceived nervous breakdowns (Nervous Breakdown Index) consultation with physicians in relation to mental health problems (Professional Persons Index), and hospitalizations for mental problems (though not necessarily in a mental hospital) (Hospitalizations Index). Parallel indices were constructed for respondents, respondents' parents, and respondents' siblings. Not all the indices were available for every relationship group. In addition, respondents answered a twenty-two item check list which had previously been used to differentiate mentally well from mentally ill populations, the Mental Health Score. ${ }^{20,21}$

The second set of indices was generally simpler than the first and was designed to give us some idea of some areas of function which might be disturbed by mental illness. These indices measured: (1) the total number of health problems reported (Total Illnesses Index); (2) whether or not medication was taken for mental health reasons (Medications Index); (3) Job Stability Index; (4) whether the individual had zero, one, or more divorces (Divorce Index); (5) involvement in automobile accidents (Accident Index); and (6) social mobility (Mobility Index). The last was simply the difference between the social class of the respondent or his sibling and the social class of the respondent's parents. This set of indices is generally referred to as the 'functional' indices. The combined indices were our operational definitions for mental health and formed the dependent variables in the data analysis.

Social class was defined according to a modification of the criteria of HollingShead. ${ }^{22}$ This definition consists of a weighted combination of occupation (classified according to his code) and education. The score derived from this combination is divided into five classes. In order to obtain comparable $N \mathrm{~s}$ in different groups, which was desirable because of the requirements of the statistical program, we collapsed Hollingshead's five class scale into three classes, designating his highest three classes as I, his fourth class as II, and his lowest class as III. Social class could not be determined from interview data in all cases, especially in the case of the respondents' relatives. In such instances the missing data was predicted from the mean social class of the relevant family. Only persons who had reached the age of 18 were included in the data analysis.

\section{Strategy of the data analysis}

Two statistical methods were used to test the null hypothesis that persons heterozygous for phenylketonuria were not more susceptible to mental illness as measured by our indices, than the NPMR and CF controls. The first was a univariate analysis of the functional and mental health indices and the second was a multivariate analysis which treatcd all the 
mental health indices as a single linear combination.* Both univariate and multivariate analyses were computed according to a program by CRAMER and HALL. ${ }^{25}$ This program was designed to handle analyses involving unequal $N \mathrm{~s}$ but requires that there be no missing data. $\uparrow$ The analyses were executed treating data from the respondents, respondents' siblings, and respondents' parents separately.

The independent variable which the study was designed to investigate is the relationship group to which the individual belongs, i.e. whether he is related to a PKU, NPMR, or CF patient. Nevertheless, variables such as social class, age, sex, and the size of the sibship to which the individual belonged had to be considered as independent factors which might affect measures of mental illness. Such variables might act to cause spurious differences between the relationship groups. This possibility was controlled by using these variables as covariates in the analysis. In fact, however, none of these covariates changed the level of significance of any effect. On the other hand, there is a body of literature concerning the effects of some of these variables (especially sex and social class) on mental illness. Such studies gave us some expectation of how the mental health indices should behave if they are comparable with other measures of mental illness. Consequently, analyses were conducted to investigate how sex and social class affected our indices.

The dependent variables in the analysis were the mental health and functional indices.

\section{RESULTS}

Locating the parents of probands was not always simple since many had lost contact with the institutions where their offspring were housed or had been diagnosed. In the end, 4.3 per cent of the original sample was never located; 4.6 per cent of the parents were known dead at the time of the interview, and $3 \cdot 1$ per cent refused to participate. An additional 2.0 per cent were not interviewed for a variety of reasons. Interviewing was completed in 91 per cent of the sample which was not known to be dead.

Social class affected the respondents' mental health indices significantly. When these indices were analyzed as though they were a single statistical unit, i.e. when the multivariate hypothesis was tested, the effect of social class was significant at the 5 per cent level of confidence (Table 1). The relative weight of the mental health indices contributing to the social class effect can be seen in Table 2 which gives the most effective linear combination of variables. It can be seen that the Alcohol and Depression Indices and Mental Health Score

\footnotetext{
* The multivariate analysis functions to select that combination of dependent variables which most effectively separates the groups whose variance is being tested. The significance of the multivariate hypothesis is not necessarily related to the significance of the univariate hypotheses, and it is possible to obtain a significant multivariate variance when no single dependent variable gives a significant univariate test. Theoretically, the multivariate hypothesis is positive if any dependent variable reaches significance, however, practically the error variance of the remaining dependent variables may produce enough statistical noise to prevent the multivariate hypothesis from reaching significance even in the presence of a proportion of significant univariate tests. This depends in part on whether or not the dependent variables actually contribute a different dimension to the analysis. Similarly, the coefficients of variables contributing to the multivariate hypothesis are determined by the extent to which that dependent variable contributes another area of variance rather than by how significantly that variable itself can separate the two groups. A number of discussions of these topics are available. ${ }^{23,24}$

$\dagger$ For this reason, missing data was treated as negative data in the scoring system used for construction of the mental health indices.
} 
Table 1. EFFECT OF SOCIO-FCONOMIC ClasS ON THE MENTAL hEALTH INDICES

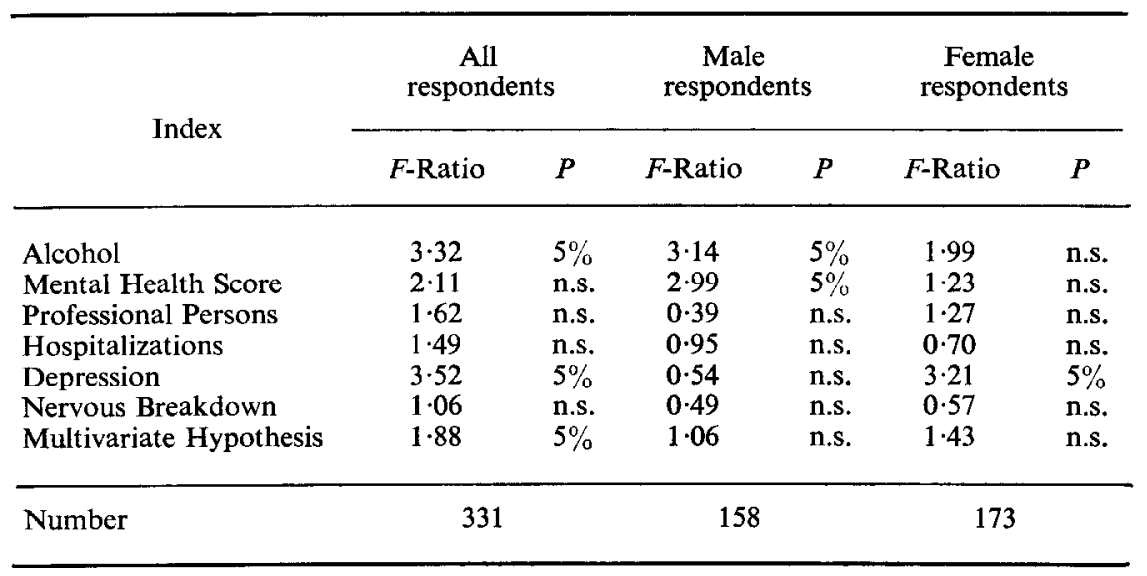

Covariates: Age and Family Size.

contribute most heavily while the Professional Persons Index makes a small contribution in the opposite direction. Neither the Nervous Breakdown nor the Hospitalizations Index appears to play a role in the social class effect. Looking at the average mental health index scores for the three social classes (Fig. 1), it can readily be seen that there is a tendency for mean values to increase as social class decreases, indicating that behavior associated with mental illness tends to be reported more frequently in the lower class groups.

When we examine the effect of social class on the variance of each independent mental health index, significant effects are found for the Alcohol and Depression Indices (Table 1).

In order to pinpoint the source of the significant differences more exactly, the effects of social class were examined for men and women separately. In these cases, we find that there is no combination of the mental health indices which gives a significant effect. There is, however, a significant effect of social class on the Depression Index for women and on the Alcohol Index for men. In addition, the men show a significant effect of social class on the Mental Health Score. Clearly social class exerts a very different effect in the two sexes.

TABLE 2. COEFficients OF INDICES CONTRIBUTING TO THE EFFECT OF SOCIAL CLASS AND SEX ON THE COMBINED MENTAL HEALTH INDICES

\begin{tabular}{l|rr}
\hline \multicolumn{1}{c}{ Index } & Social class & \multicolumn{1}{c}{ Sex } \\
\hline Alcohol & 0.59 & -0.51 \\
Depression & 0.57 & 0.56 \\
Mental Health Score & 0.49 & 0.38 \\
Professional Persons & -0.25 & 0.39 \\
Hospitalizations & 0.07 & -0.06 \\
Nervous Breakdown & 0.06 & 0.44 \\
\hline
\end{tabular}




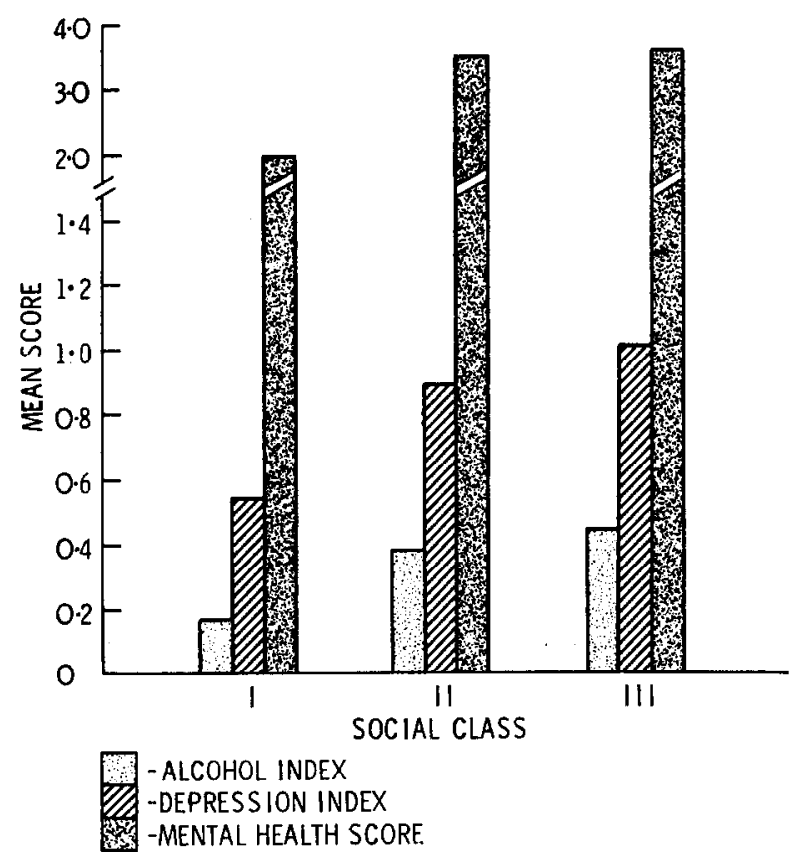

FIG. 1. Respondents' mean Alcohol Depression and Mental Health Scores by social class.

Social class was not found to affect the mental health indices of either the respondents' siblings or parents, but did affect many of the functional indices, not only for the respondents but for their siblings and parents. Altogether, social class has a small effect which is in the direction anticipated, of increasing difficulty associated with decreasing social status.

The mental health indices are sensitive to the effect of sex not only for the respondents but also for the respondents' relatives (Table 3). Sex affects the linear combination of the mental health indices at the $0 \cdot 1$ per cent level of confidence for the respondents' siblings and parents as well as the respondents themselves. Table 2 shows the relative importance of indices contributing to this effect in the case of the respondent, and it can be seen that with exception of the Hospitalizations Index, all the indices contribute to a similar extent.

Inspection of the mean scores of men and women (Table 4) shows differences which might very well have been anticipated a priori, if our indices bear the relation to mental illnesses which was intended. Men appear to have more drinking problems than women, and women score higher on questions having to do with depression. Women report that they felt they were going to have a nervous breakdown more often than men. Women respondents tended to seek medical aid for mental health problems more often than men, and tended to have more positive responses on the Mental Health Score. They reported more illnesses, took more pills for their problems, and had fewer accidents.

The test of the hypothesis that group (i.e. whether an individual is related to a PKU, NPMR, or CF patient) would account for variance in the mental health indices can be seen in Table 3. None of the analyses, either univariate or multivariate, reach statistical significance. This is in marked contrast to the highly significant effect of sex. The effect of 


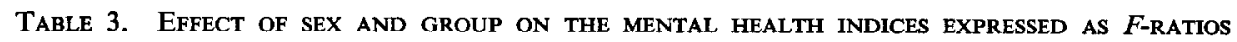

\begin{tabular}{|c|c|c|c|c|c|c|}
\hline \multirow{2}{*}{ Index } & \multicolumn{2}{|c|}{ Respondents } & \multicolumn{2}{|c|}{$\begin{array}{l}\text { Respondents' } \\
\text { siblings }\end{array}$} & \multicolumn{2}{|c|}{$\begin{array}{l}\text { Respondents' } \\
\text { parents }\end{array}$} \\
\hline & Sex & Group & Sex & Group & Sex & Group \\
\hline Alcohol & $13 \cdot 36 \ddagger$ & $2 \cdot 10$ & $9 \cdot 88+$ & $1 \cdot 30$ & $32 \cdot 11 \ddagger$ & $2 \cdot 12$ \\
\hline Depression & $16 \cdot 17 \ddagger$ & $1 \cdot 31$ & $13 \cdot 09 \ddagger$ & $1 \cdot 86$ & $9 \cdot 52 \dagger$ & 0.29 \\
\hline Professional Persons & $7 \cdot 95^{*}$ & 0.20 & 0.07 & $1 \cdot 48$ & $1 \cdot 11$ & 0.56 \\
\hline Hospitalizations & $0 \cdot 16$ & $2 \cdot 17$ & 1.07 & $0 \cdot 13$ & 0.02 & 0.59 \\
\hline Nervous Breakdown & $9 \cdot 98 \dagger$ & 0.42 & - & - & - & - \\
\hline Mental Health Score & $7 \cdot 42^{*}$ & $1 \cdot 44$ & - & - & - & 一 \\
\hline Senility & - & - & 0.51 & $0 \cdot 29$ & 0.07 & $0 \cdot 16$ \\
\hline Multivariate Hypothesis & $8 \cdot 52 \ddagger$ & $1 \cdot 47$ & $5 \cdot 37 \ddagger$ & $1 \cdot 43$ & $7 \cdot 12 \ddagger$ & 1.07 \\
\hline Covariate & $\begin{array}{l}\text { Age and } \\
\text { family } \\
\text { size }\end{array}$ & $\begin{array}{l}\text { Age and } \\
\text { family } \\
\text { size }\end{array}$ & $\begin{array}{l}\text { Socio- } \\
\text { economic } \\
\text { class }\end{array}$ & Age & $\begin{array}{l}\text { Socio- } \\
\text { economic } \\
\text { class }\end{array}$ & - \\
\hline Number & \multicolumn{2}{|c|}{331} & \multicolumn{2}{|c|}{1,159} & \multicolumn{2}{|c|}{637} \\
\hline
\end{tabular}

* Significant at the $1 \cdot 0 \%$ level of confidence.

+ Significant at the $0.5 \%$ level of confidence.

$\$$ Significant at the $0 \cdot 1 \%$ level of confidence.

group on the functional variables can be seen in Table 5 and the mean scores for all variables in Table 6. The only variable on which group exerts a significant effect is divorce; however, this effect of group on the Divorce Index is not seen either for the respondents' parents or for the respondents' siblings. In addition, when we examine the mean score of the respondents' Divorce Index on the three groups, we find that the mean indices of the PKU

TABle 4. Mean scores of Mental health and FunCtional INDICES FOR MEN AND WOMEN RESPONDENTS

\begin{tabular}{|c|c|c|}
\hline Index & Men & Women \\
\hline Number & 158 & 173 \\
\hline Alcohol & 0.54 & $0.17 \ddagger$ \\
\hline Mental Health Score & $2 \cdot 13$ & $3 \cdot 36 \dagger$ \\
\hline Professional Pcrsons & 0.17 & $0.36 \dagger$ \\
\hline Hospitalizations & 0.08 & 0.08 \\
\hline Depression & 0.52 & $1 \cdot 07 \ddagger$ \\
\hline Nervous Breakdown & 0.40 & $0.77^{\ddagger}$ \\
\hline Total Illnesses & 1.69 & $2 \cdot 12^{*}$ \\
\hline Medications & 0.04 & $0 \cdot 13 \ddagger$ \\
\hline Job Stability & 1.02 & — \\
\hline Mobility & 0.51 & 0.49 \\
\hline Divorce & $0 \cdot 17$ & $0 \cdot 20$ \\
\hline Accidents & $0 \cdot 60$ & $0 \cdot 20 \ddagger$ \\
\hline
\end{tabular}

* Differs from men at the $5 \%$ level of confidence.

$\uparrow$ Differs from men at the $1 \%$ level of confidence.

\$ Differs from men at the $0.1 \%$ level of confidence. 
TABLE 5. EFFECT OF GROUP ON THE FUNCTIONAL INDICES

\begin{tabular}{|c|c|c|c|c|c|c|}
\hline \multirow{2}{*}{ Index } & \multicolumn{2}{|c|}{ Respondents } & \multicolumn{2}{|c|}{$\begin{array}{l}\text { Respondents' } \\
\text { siblings }\end{array}$} & \multicolumn{2}{|c|}{$\begin{array}{c}\text { Respondents' } \\
\text { parents }\end{array}$} \\
\hline & $F$-Ratio & $P$ & $F$-Ratio & $P$ & $F$-Ratio & $P$ \\
\hline Job stability & $2 \cdot 74$ & n.s. & $2 \cdot 54$ & n.s. & $1 \cdot 04$ & n.s. \\
\hline Divorce & $4 \cdot 03$ & $5 \%$ & $0 \cdot 28$ & n.s. & $2 \cdot 07$ & n.s. \\
\hline Accidents & $0 \cdot 31$ & n.s. & $0 \cdot 70$ & n.s. & 一 & - \\
\hline Mobility & $0 \cdot 33$ & n.s. & 0.05 & n.s. & 一 & 一 \\
\hline Total Illnesses & 0.00 & n.s. & - & 一 & 一 & 一 \\
\hline Medications & $0 \cdot 12$ & n.s. & 一 & - & 一 & 一 \\
\hline Number & \multirow{2}{*}{\multicolumn{2}{|c|}{$\begin{array}{c}331 \\
\text { Socio-economic } \\
\text { class }\end{array}$}} & \multirow{2}{*}{\multicolumn{2}{|c|}{$\begin{array}{c}1,159 \\
\text { Socio-economic } \\
\text { class }\end{array}$}} & \multirow{2}{*}{\multicolumn{2}{|c|}{637}} \\
\hline Covariate & & & & & & \\
\hline
\end{tabular}

and NPMR groups are similar while the mean index for the CF group is significantly lower (Table 6). These figures indicate that the variance cannot be attributed to heterozygosity for phenylketonuria but is associated with some factor that differentiates parents of mentally retarded children (including phenylketonurics) from the parents of children with cystic fibrosis in our sample. Since many of the parents in our sample had children in state institutions, it may be that some of the factors that lead to the institutionalization of a child were operative here.

The possibility remained that the presumed effect of heterozygosity might act on a particular subset of the population we had investigated. It seemed likely that if such an effect

TABLE 6. MEANS OF FUNCTIONAL AND MENTAL HEALTH INDICES FOR PARENTS OF PHENYLKETONURIC, NON-PHENYLKETONURIC MENTALLY RETARDED AND CYSTIC FIBROSIS PATIENTS

\begin{tabular}{|c|c|c|c|}
\hline \multirow[b]{2}{*}{ Index } & \multicolumn{3}{|c|}{ Group } \\
\hline & Phenylketonuric & $\begin{array}{l}\text { Non-Phenylketonuric } \\
\text { Mental Retardation }\end{array}$ & Cystic Fibrosis \\
\hline Number & 108 & 102 & 121 \\
\hline Alcohol & 0.28 & 0.30 & 0.45 \\
\hline Mental Health Score & $2 \cdot 73$ & $3 \cdot 13$ & $2 \cdot 83$ \\
\hline Depression & 0.81 & $1 \cdot 24$ & 0.68 \\
\hline Nervous Breakdown & 0.57 & 0.65 & $0 \cdot 56$ \\
\hline Professional Persons & $0 \cdot 27$ & $0 \cdot 29$ & $0 \cdot 26$ \\
\hline Hospitalizations & $0 \cdot 14$ & 0.05 & 0.05 \\
\hline *Job Stability & 0.98 & $1 \cdot 28$ & 0.86 \\
\hline Accidents & $0 \cdot 34$ & 0.43 & 0.41 \\
\hline Total Illnesses & $1 \cdot 89$ & $1 \cdot 91$ & $1 \cdot 92$ \\
\hline Medications & 0.43 & 0.38 & $0 \cdot 38$ \\
\hline Divorce & 0.27 & $0 \cdot 22$ & $0 \cdot 08$ \\
\hline Mobility & 0.50 & 0.47 & 0.53 \\
\hline
\end{tabular}

* Calculated for men only. PKU $N=49$, NPMR $N=51$, and CF $N=58$. 
did exist, it would be found in some biologically determined group in the population. Age and sex are the two most obvious variables which one might expect to interact with genetic factors. Both these parameters have been proposed as variables influencing the mental illness producing effects of heterozygosity for phenylketonuria. PENROSE ${ }^{8}$ in his original study of a family in which depressions and phenylketonuria appeared to be associated, suggested that most of the individuals affected had a late age of onset to their mental illness. THOMPSOn, ${ }^{10}$ on the other hand, suggests that the individuals she found to be mentally ill in the families of phenylketonurics studied, suffered from life-long difficulties. She also suggests that the mental problems are most commonly found in the male members of the families studied. If indeed, there was some interaction between heterozygosity and age in respect to mental illness, then such an effect should have been seen in the data on the grandparents of the phenylketonuric child. No such effect appears (Table 3). In addition, such an interaction should have been demonstrated by a two-way analysis of variance between group and age. Such analyses did not reach significance for either the respondents or the respondents' relatives.

The second hypothesis, that heterozygosity might predispose one sex to mental illness was tested by repeating the analysis for men and women separately (Table 7). It can readily be seen that there is no effect of group on the univariate or multivariate analysis for either sex. This is in contrast to our earlier demonstration that social class can affect the two sexes differently. Supporting the negative results produced by separate analysis of data from men and women, was analysis of variance of the interaction hetween sex and group for the respondents and their relatives. None of these two-way analyses reached significance.

The only significant interaction between group and another variable was an interaction between group and social class for the respondents. This interaction, significant at the 5 per cent level of confidence, could be attributed to excessively high scores on the Alcohol Index for CF parents in Social Class III. Since this finding was not repeated by data for either the respondents' parents or siblings it seems likely that this interaction represents a statistical accident.

TABLE 7. EFFECT OF GROUP ON THE MENTAL HEALTH INDICES ANALYzed SEPARATELY FOR MEN AND WOMEN RESPONDENTS

\begin{tabular}{lccccc}
\hline \multirow{2}{*}{\multicolumn{1}{c}{ Index }} & \multicolumn{2}{c}{ Men } & \multicolumn{2}{c}{ Women } \\
\cline { 2 - 5 } & $F$-Ratio & $P$ & $F$-Ratio & $P$ \\
\hline Alcohol & 0.80 & n.s. & 1.97 & n.s. \\
Mental Health Score & 0.32 & n.s. & 2.01 & n.s. \\
Professional Persons & 0.46 & n.s. & 0.95 & n.s. \\
Hospitalizations & 1.48 & n.s. & 1.36 & n.s. \\
Depression & 0.09 & n.s. & 2.12 & n.s. \\
Nervous Breakdown & 0.32 & n.s. & 1.63 & n.s. \\
Multivariate Hypothesis & 0.78 & n.s. & 1.43 & n.s. \\
\hline Number & & 158 & & & \multicolumn{2}{c}{173} & \\
\hline
\end{tabular}

Covariates: age and family size. 


\section{DISCUSSION}

We have presented the results of a study designed to investigate the possibility that persons who presumably have a particular biochemical liability, relative phenylalanine hydroxylase deficiency, have more mental illness than other individuals. The first problem generated by the hypothesis was how to choose the population to be investigated. The rate of heterozygosity in the general population has been estimated to lie between one out of sixty and one out of one-hundred persons. This is a rate which is high enough to affect a large number of people but low enough so that in the absence of a cheap, convenient test it would have been difficult to select heterozygotes from a general population. Consequently, we studied families in which heterozygosity could be presumed from the presence of a phenylketonuric child. Such a choice leads immediately to certain difficulties. In the first place, the parents of a phenylketonuric child will certainly have been subject to an unusual amount of stress, both emotional and financial, because of the serious nature of the affected child's disability. Such stress might act to increase the amount of emotional disorder in these families and precludes comparison with a sample of so-called normal families who have not suffered similar hardships.

Because of the possible effect of the retarded child on the family, both control groups were chosen to have similar problems. In the case of the NPMR group, with the exception that most of the children suffered from non-hereditary mental retardation, the illness of the affected member was highly similar to that of the phenylketonuric. Similarly, parents of patients with cystic fibrosis were chosen as a second control group because cystic fibrosis represents a recessive hereditary disease which is severe, chronic and most often manifests itself early in childhood. The disease generally terminates fatally sometime during adolescence. In many ways, a loss of a child through death is analogous to the loss of a child through severe retardation leading to institutionalization. It seemed likely that families with children with cystic fibrosis would suffer from stresses similar to those imposed on a family with a mentally retarded child.

All three of these groups represented a special population in the sense that the parents of these patients had been exposed to highly stressful situations. However, it seemed reasonable to suppose that the grandparents and aunts and uncles of the affected child would be relatively untouched by the proband's illness. Nevertheless, half of these relatives should be heterozygous for PKU in the PKU group. If there had been any effect of PKU on the mental health of the parents, similar, though diluted effects should have been observed among these relatives. It was on the basis of this reasoning that the interview was extended to include information about the aunts, uncles and grandparents of the affected child. It is true, however, that our information about the non-parent relatives is probably less reliable since it represents a report by the respondent on other persons rather than a self report. As might have becn expected, information about the respondents' relatives is less complete than information provided by the respondent about himself.

The second set of problems generated by the hypothesis revolved around what would constitute a reasonable way of estimating mental illness. Two considerations played a primary role in our decision to approach the problem through a formal interview schedule and coding procedure. The first of these was our desire to make as explicit as possible what 
was actually investigated, and the second was the wish to reduce bias in the conduct of the study as much as possible.

Since the problem of trying to evaluate the relative prevalence of mental illness in a group is similar to that of identifying a 'psychiatric case' in a non-patient population, we seriously considered the possibility of using psychiatric evaluations either as our basic research tool or as a means of evaluating the interview schedule. This is essentially the technique that has been used in the most recent and elaborate psychiatric field studies. ${ }^{26,27}$ However, there are many difficulties in assigning the status of being a 'psychiatric case' to a person in a nonpatient population. There is no standardized, validated, diagnostic test which enables the researcher to determine the presence or absence of mental illness in individuals, ${ }^{28,29}$ and psychiatric diagnosis is not reliable. ${ }^{30,31}$ This situation has caused considerable difficulty in field studies of psychological disorder. According to a recent review of such studies ${ }^{15}$ prevalence rates of mental illness have varied from less than 1 per cent to over 60 per cent. It has been suggested that factors such as thoroughness of data collection, presence or absence of physical examinations, and the decade in which the study was done, all contribute to this variability. But it seems likely that an important factor contributing to the variety of prevalence rates for mental illness must be at least partly a function of the lack of reliability of psychiatric diagnosis on the one hand, and the current lack of ability to specify how a diagnosis or rating is made on the other. It was largely to avoid these problems that we developed the mental health indices which are the operational definitions of mental illness used as dependent variables in this analysis. These constructs lack the validity of a true psychiatric diagnosis, but have the advantage of being reproducible, specifying clearly what was investigated, and lending themselves readily to control for bias.

Since the indices were developed for our study, it seems reasonable to ask what is their validity, if any. All the constructs have a certain face validity arrived at by using concrete questions, easily related to mental illness, for the scoring system. ${ }^{19}$ In addition, we have shown elsewhere that the Depression and Nervous Breakdown Indices, and the Mental Health Score are correlated with visits to professional persons for mental health problems and hospitalizations for similar reasons. Such correlations indicate that the indices tapped problem areas which were viewed as serious by the respondents. Since 12 per cent of the visits to doctors by respondents and 24 per cent of visits by relatives represented contacts with psychiatrists, these correlations can be taken to indicate a certain degree of validation of the indices as estimators of psychiatric disease.

The Mental Health Score has been validated in a number of studies. Items were originally selected to differentiate between a mentally well population and psychiatric patients. ${ }^{20}$ Since then, the Score has been reported to differentiate between patients on the admitting ward of a mental hospital and several normal populations. ${ }^{21}$ In addition, a survey of records at Michigan State Hospitals for the mentally ill demonstrated that all hospitalized respondents (including three who were hospitalized after the time of the interview) scored well above average on one or more indices other than Hospitalizations. In the case of the respondents' relatives, only 81 per cent of the hospitalizations were reported and only 67 per cent of these relatives scored on other mental health indices. In spite of the low reporting on relatives, these findings tend to validate the indices as measures of mental health.

In attempting to evaluate the merits of the indices as measures of mental health, it is 
worth noting that these measures behave as one would expect on the basis of clinical knowledge and in conformity to the results of other psychiatric field studies. So we find men averaging higher scores on the Alcohol Index and women on the Depression Index, which one might anticipate if the former is related to alcoholism and the latter to depressions.

Women report more nervous breakdowns, answer more questions on the Mental Health Score and seek more help from professional persons than men, findings similar to those of GURIN et $a .^{32}$ on a national sample. LEIGHTON et al. ${ }^{20}$ in a study of a Nova Scotia community also find women scoring higher than men in most of their symptom patterns. According to Dowhrenwend and Dowhrenwend ${ }^{15}$ eleven out of thirteen field studies conducted since 1950 assign higher rates of psychological disorder to women than to men. Certainly our findings fall into the same pattern.

The Dowhrenwends have also pointed out an increasing prevalence of mental disorder with decreasing social class is the most consistent finding of field studies of psychiatric disorder and the results of our study are in the same direction in spite of the fact that the level of significance is low. The fact that the mental health indices are sensitive to the effects of sex and social class can be taken as an indication that this set of tools belongs in the same universe with other devices used to assess mental health in field studies.

In view of the fact that we failed to differentiate between persons presumed heterozygous for phenylketonuria and the control groups using the mental health indices as measures of mental illness, it is pertinent to ask whether or not these indices are actually capable of discriminating between groups which do differ in the state of their mental health. There is some evidence, other than the social class and sex effects mentioned above, that they can. A number of workers have pointed out that admission rates to mental hospitals are higher for divorced persons than other marital groups. ${ }^{33,34}$ This would lead one to suspect that divorced persons in a population should show more mental health problems than nondivorced individuals. In analyses similar to those described in this paper, it has been found that the mental health indices discriminated significantly between divorced and nondivorced persons at high levels of confidence for the respondents' parents and siblings as well as the respondents. ${ }^{35}$ This gives us some confidence that the indices can discriminate between groups which one might predict to have real differences in mental health and that they can do so for the relatives as well as the respondents.

It is, of course, always very difficult to demonstrate that a hypothesis is not so, and it remains possible that heterozygosity for phenylketonuria is associated with mental illness in the areas we have investigated, but a level too low for our tcchniques to detect. It seems clear that if such an effect exists, it is a factor which is considerably less powerful than the social factor of marital status. Even if such an effect exists it seems unlikely that it would make a very useful tool for further investigation. We are necessarily limited in our conclusions to the tools we used as measures of mental illness. Perhaps other psychiatric assessments might show differences.

The possibility always remains that heterozygosity is associated with deficiencies which might be demonstrated by other lines of investigation. It has been recently shown, for example, that heterozygosity for phenylketonuria is associated with an increased susceptibility to metrazol-induced convulsions. ${ }^{36}$ It remains entirely possible that other specific stimuli will be demonstrated to have altered effects in such persons. Nevertheless, the 
general hypothesis that persons heterozygous for phenylketonuria have more mental illness than other persons seems less tenable as a result of this study.

\section{SUMMARY}

(1) This paper presents the results of a field study designed to investigate the hypothesis that persons presumed heterozygous for phenylketonuria are more vulnerable to mental disorder than other persons. Three-hundred-and-thirty-one persons were interviewed, including 108 parents of phenylketonuric offspring, 102 parents with nonphenylketonuric mentally retarded offspring, and 121 parents of children with cystic fibrosis.

(2) Information was collected by means of a standard interview schedule which inquired into mental health problems of the interviewees as well as their parents and siblings. Interviews were coded according to an explicit code. Mental Health was evaluated by a set of indices constructed by assigning numerical values to certain items in the code and summing related items. These indices served as operational definitions of mental illness.

(3) Analysis of variance was used to evaluate data derived.

(4) Decreasing social class appcared to be associated with increasing scores on the indices. In addition, men and women scored significantly differently on many of the indices. In general, differences due to sex and social class were in the direction which would have been expected if the indices had been measuring the problem areas we were trying to evaluate.

(5) The parents of phenylketonuric children did not score differently from the other two groups, indicating that they were not more susceptible to mental health problems than the controls, at least as measured by our operational definitions.

(6) Some of the problems associated with field studies of psychiatric disease are discussed.

Acknowledgements-This work was supported by career development award 5-K3-MH-9403 and research grant $\mathrm{MH}-08592$ from the National Institute of Mental Health. We wish especially to thank the parents who so generously donated their time and the interviewers who traveled far beyond their usual routes with remarkable energy and enthusiasm. We are indebted to the Michigan Department of Maternal and Child Health, the Michigan Department of Public Instruction, and the Michigan Department of Mental Health for giving access to information and patients in institutions and children in Special Education Classes. We are also indebted to Dr. RoBert GREGG who provided the names of some of the cystic fibrosis patients. I wish to thank Dr. ERNEST HARBurg who acted as study dircetor to the project during its first year, Dr. ROBERT KAHN for continuing consultation and encouragement, Dr. DAVID LEWIT for consultation, and Dr. SIDNEY Совв for many helpful conversations. I am grateful to Dr. J. E. K. SMrTH for statistical consultation and Mr. Paul IsaAc for technical assistance with statistics and programming, Mr. Charles Stallman for technical assistance, and Mrs. DIANE RAY and Mrs. Barbara LuDWIG whose faithful secretarial services played a crucial role in the conduct of the study.

\section{REFERENCES}

1. Knox, W. E. Phenylketonuria. In The Metabolic Basis of Inherited Disease, Stambury, J. B., WyngaARden, J. B. and Fredrickson, D. S. (Editors), McGraw-Hill, New York, 1960.

2. Allen, R. J. and Gibson, R. M. Phenylketonuria with normal intelligence. Am. J. Dis. Child. 102, $115,1961$.

3. Wrighi, S. W. and Tarjan, G. Phenylketonuria. Am. J. Dis. Child. 93, 405, 1957. 
4. Sutherland, B. S., Berry, H. K. and Shirkey, H. C. A syndrome of phenylketonuria with normal intelligence and behavior disturbances. J. Pediat. 57, 521, 1960.

5. WONG, P. W., O'FLYNN, M. E. and INOUYE, T. Micromethods for measuring phenylalanine and tyrosine in serum. Clin. Chem. 10, 1098, 1964.

6. RENSON, J., WEISSBACK, H. and UNDENFRIEND, S. Hydroxylation of tryptophan by phenylalanine hydroxylase. J. biol. Chem. 237, 2261, 1962.

7. FøluING, A. Über Ausscheidung von Phenylbrenztraubensaure in den Harn als Stoffwechselanomalie in Verbindung mit Imbezillität. Hoppe-Seyler's Z. physiol. Chem. 227, 169, 1934.

8. PenRose, L. S. Inheritance of phenylpyruvic amentia (phenylketoraria). Lancet II, 192, 1935.

9. Munro, T. A. Phenylketonuria: Data on forty-seven British families. Ann. Eugen. 14, 60, 1947.

10. Thompson, T. H. Relatives of phenylketonuric patients. J. ment. Defic. Res. 1, 67, 1957.

11. Perry, T. L., Tischler, B. and Chapple, J. A. The incidence of mental illness in the relatives of individuals suffering from phenylketonuria or mongolism. J. Psychiat. Res. 4, 51, 1966.

12. KNOX, W. E. and HsIA, D. Y. Y. Pathogenetic problems in phenylketonuria. Am. J. Med. 22, 687, 1957.

13. AlleN, R. J., LowreY, G. L. and Wilson, J. L. The search for phenylketonuria in Michigan. J. Mich. St. med. Soc. 59, 1089, 1960.

14. Penrose, L. S. The Biology of Mental Defect. Grune \& Stratton, New York, 1963.

15. Dowhrenwend, B. P. and Dowhrenwend, B. S. The problem of validity in field studies of psychological disorder. J. abnorm. Psychol. 70, 52, 1965.

16. LADU, B. N. and Michael, P. J. An enzymatic spectrophotometric method for the determination of phenylalanine in blood. J. Lab. clin. Med. 55, 491, 1960.

17. HALLGREN, B. and SJÖGREN, T. A clinical and genetico-statistical study of schizophrenia and low grade mental deficiency in a large Swedish rural population. Acta psychiat. neurol. scand. Suppl. 140, 1959.

18. MUEHL, D. A Manual for Coders. Institute for Social Research, Ann Arbor, 1961.

19. Blumenthal, M. D. Sex as a source of heterogeneity in a mental health survey. J. Psychiat. Res. 5, 75, 1967.

20. LANGNER, T. S. A twenty-two item screening score of psychiatric symptoms indicating impairment. J. Hlth. Hum. Behav. 3, 269, 1963.

21. Manis, J. G., Brawer, M. J., Hunt, C. L. and Kercher, L. C. Validating a mental health scale. Am. Sociol. Rev. 28, 108, 1963.

22. Hollingshead, A. B. Two factor index of social position. 1965 Yale Station, New Haven, 1957.

23. Sмттн, J. E. K. Multivariate Analysis of Variance and Discriminant Functions. Preprint No. 177, Mental Health Research Institute, University of Michigan, Ann Arbor, 1965.

24. Smith, H., Gnanadesikan, R. and Hughes, J. B. Multivariate analysis of variance (Manova). Biometrics 18, 22, 1962.

25. HaLl, C. E. and Cramer, E. M. A general purpose program to compute multivariate analysis of variance on an IBM 7090 computer. George Washington University Biometric Laboratory, Washington, 1960.

26. Leighton, D. C., Harding, J. S., Macklin, D. B., Macmillan, A. M. and Leighton, A. H. The Character of Danger, Vol. III, The Stirling County Study of Psychiatric Disorder and Sociocultural Environment. Basic Books, New York, 1963.

27. Srole, L., Langner, T. S., Michael, S. T., Opler, M. K. and Rennie, T. A. C. The Midtown Manhattan Study, Vol. I, McGraw-Hill, New York, 1962.

28. Hollingshead, A. B. Some issues in the epidemiology of schizophrenia. Am. Sociol. Rev. 26, 5, 1961.

29. HetzNecker, W., Gardner, E. A., OdOROFF, C. L. and TuRNER, R. J. Field Survey Methods in Psychiatry. Archs gen. Psychiat. 15, 427, 1966.

30. AsH, P. The reliability of psychiatric diagnosis. J. abnorm. soc. Psychol. 44, 272, 1949.

31. BLum, R. H. Case identification in psychiatric epidemiology: Methods and problems. Milbank meml Fund q. Bull. 40, 253, 1962.

32. GURIN, G., VeroFf, J. and FeLd, S. Americans View Their Mental Health. Basic Books, New York, 1960.

33. MalzBerg, B. Marital status and the incidence of mental disease. Int. J. soc. Psychiat. 10, 19, 1964.

34. ØDEGARD, O. Marriage and mental health. Acta psychiat. neurol. scand. Suppl. 80, 153, 1952.

35. Blumenthal, M. D. Comparative mental health of divorced and never divorced persons. Archs gen. Psychiat. (In press.)

36. Nakai, K., Hidenobu, I., Kakimoto, Y., Hishikawa, Y., Sano, I. and Kaneko, Z. A low metrazol threshold in the heterozygotes of phenylketonuria. J. nerv. ment. Dis. 141, 436, 1966. 